\title{
Research on Risk Evaluation of New Rural Financial Institutions
}

\author{
Zhongyang $\mathrm{Niu}^{1,}$, and Kang $\mathrm{Jin}^{2, \mathrm{~b}}$ \\ ${ }^{1}$ Nanjing University of Finance and Economics, Nanjing 210023, China; \\ ${ }^{2}$ School of Marketing and Logistics Management, Nanjing University of Finance and Economics, \\ Nanjing 210023, China.
}

aoasis322@126.com, bmr_joyking@aliyun.com

Keywords: New rural financial institutions, risk assessment, risk management.

\begin{abstract}
The development of new rural financial institutions in Jiangsu Province has played an important role in supporting agriculture services for more than a decade, and it is also inevitably faced with financial risks. In this paper, by reviewing the literatures on the risk management of traditional rural financial institutions and new rural financial institutions, this paper developed the risk evaluation system of new rural financial institutions, focused on the inclusion of ethical risk in the scale and then carried out empirical analysis of some examples to put forward countermeasures and recommendations of the new rural financial institutions risk management. For the new rural financial institutions, it is necessary to focus on risk control, such as safety, liquidity and capital adequacy, and to improve the efficiency and development capability, but also to guard against the risks caused by business growth inflated.
\end{abstract}

\section{Introduction}

According to the provisions of the CBRC, the new rural financial institutions (NRFI) are the new political financial institutions that serve the "Three Rural", mainly including three categories, village banks, rural credit cooperatives and loan companies. Since 2006, NRFI have played an important role in resolving the difficulties in loans of farmers and rural small and medium-sized enterprises, have also fully improved the rural financial system, and inevitably, NRFI were faced with financial risks. The importance of risk prevention in NRFI is becoming more and more prominent. There are also many problems in risk management while the NRFI system had achieved development results, such as legal risk, credit risk, operational risk, liquidity risk and regulatory risk, etc. [1]. The risk of NRFI is serious, the prevention and management of risk is necessary and urgent. The research on the risk type, mechanism and the quantitative evaluation of risk is the realistic demand of the risk management of NRFI.

The establishment of a sound and scientific risk evaluation system is a necessary prerequisite for risk management of NRFI. At present, the research on the NRFI mainly focused on the types of risks and the mechanism of risk triggering, however, the results of the quantitative evaluation of the risks of the NRFI based on the evaluation system are poor. And there is a general lack of empirical research in existing researches, the existence of this phenomenon hindered verifying the rationality and scientific of evaluation system. We will further revise and improve the evaluation system of the risk of the NRFI on the basis of the existing research conclusions.

\section{Literature References}

By focusing on the Chinese domestic literature research in the field of NRFI, we found that the focus of industry and academia research both focused on the risk resource analysis of NRFI and risk assessment management. About the analysis on risk causes. Based on the theory of information asymmetry, Xiaoguang Gao studied the default risk and moral risk of NRFI due to information asymmetry [2]. Guangwei Tian summarized the causes of the NRFI risk into five categories, including government policy-oriented risk, capital operation risk, default risk, operational risk and 
operating cost risk [3]. The above inductions and summaries of the risk types of NRFI are the basis and prerequisite for risk assessment and management.

We especially focused on learning from the status and research results of risk assessment management research. JY Wang used the AHP and Expert Questionnaire method to determine the factors related to the management of the financial institutions as internal factors, including capital adequacy, safety, liquidity, profitability, development ability and staff quality, etc.. On the other hand, external risk factors included national policies, laws and regulations, rules and regulations, social environment, local economic development, local firm size and development, etc. [4]. Based on the particularity of the NRFI risk, Wenpei Tan used AHP to construct the risk evaluation and early warning index system of NRFI, including quantitative and qualitative evaluation indexes. Quantitative indicators included capital adequacy, liquidity, safety, efficiency and comprehensive development capabilities, and qualitative ones included management capacity and finance regulation [5]. The development history of NRFI was short, and the research results on the evaluation of the subject were lackluster. But in general, the comprehensive evaluation of NRFI risk could be summarized as internal indexes and external indexes. The internal indicators were generally quantitative indicators, mainly include capital adequacy, liquidity, security, profitability, development ability, management ability, etc., they measured the objective level of the system. External indicators were generally qualitative ones, include financial legal system, financial supervision, economic environmental and other dimensions, mainly evaluated the soft environment inside and outside the system. Due to the different policy environment, economic environment, cultural environment, geographical environment, we need do some adjustment about risk assessment system to adapt to different environment.

\section{Scale Design and Testing}

We summarized the researches of the above-mentioned experts and scholars on the risk types, risk assessment and risk management of NRFI, and we thought that it was necessary to consider the moral risk caused by moral factors in the comprehensive evaluation of new rural financial system risk. Moral risk was mentioned by Xiaoguang Gao and Caihong Lan [6]when studying the types of NRFI system risks. Unfortunately, moral factors were not reflected in the risk assessment system. Any financing activity was faced with the moral risk of the borrowers [7], for the new rural financial system, we also need to consider the important role of moral risk. From the results of combing the literatures, it was generally believed that moral risk was mainly influenced or caused by factors such as the level of information symmetry, the moral level of financial institutions and the moral level of borrowers, etc.. The moral risk caused by information asymmetry was more common, because the NRFI had less knowledge of the reputation, financial situation and the risk and benefit of the loan project [8]. The moral risk of the financial institution and the risk of the borrower's moral level were reflected in the fact that the insured financial institution invested in high-risk projects in pursuit of high returns, while the borrowers carried out high-risk projects in pursuit of low interest rates [9]. We used the level of information symmetry construction, the moral level of financial institutions and the moral level of borrowers as the three sub-dimensions of moral risk assessment.

In summary, we chose capital adequacy, liquidity, safety, profitability and development ability as the quantitative indexes, and chose economic environment, financial supervision and moral construction as the qualitative ones, a total of 2 primary indicators and 8 secondary indicators. In order to improve the rationality of the evaluation dimensions we chose for NRFI risk, we used the expert questionnaire method to carry out the preliminary selection and revision of the scale. Considering the data availability in empirical analysis, we finally designed 19 third-level indicators to measure above eight main dimensions.

\section{Empirical Analysis and Suggestions}

Further, we determined the weight of indexes by AHP, and further integrated experts' opinions for fuzzy comprehensive evaluation. We sent out a total of 20 questionnaires by interview and E-mail. 
Experts gave 1 9 value to different levels of risk factors according to the importance of the different factors to determine matrixes of different layers and different factors, and we finally got the weight of all dimensions and indexes as shown in Table 1. The results of the consistency test of the judgment matrix at all levels showed that CR was all less than 0.1, and the statistical test was carried out successfully, indicating that the weights of the above dimensions and indexes were valid.

Table 1. Risk Evaluation Index System with Weight of NRFI

\begin{tabular}{|c|c|c|c|c|c|c|}
\hline $\begin{array}{l}\text { Target } \\
\text { layer }\end{array}$ & $\begin{array}{l}\text { Level } 1 \\
\text { indicato } \\
\quad \mathrm{r} \\
\end{array}$ & $\begin{array}{l}\text { Level } 1 \\
\text { weight }\end{array}$ & Level 2 indicator & $\begin{array}{l}\text { Level } 2 \\
\text { weight }\end{array}$ & $\begin{array}{l}\text { Level } 3 \\
\text { indicator }\end{array}$ & $\begin{array}{l}\text { Level } 3 \\
\text { weight }\end{array}$ \\
\hline \multirow{19}{*}{$\begin{array}{l}\text { NRFI } \\
\text { Risk }\end{array}$} & \multirow{11}{*}{$\begin{array}{l}\text { Internal } \\
\text { factors }\end{array}$} & \multirow{11}{*}{0.7500} & \multirow{2}{*}{ Capital adequacy } & \multirow{2}{*}{0.1782} & Capital adequacy ratio & 0.1426 \\
\hline & & & & & Provision coverage & 0.0356 \\
\hline & & & \multirow{2}{*}{ Liquidity } & \multirow{2}{*}{0.1450} & Deposit and loan ratio & 0.0533 \\
\hline & & & & & Percentage of funds split & 0.0917 \\
\hline & & & \multirow{3}{*}{ Safety } & \multirow{3}{*}{0.2795} & Nonperforming loan rate & 0.1118 \\
\hline & & & & & Single largest customer loan ratio & 0.1118 \\
\hline & & & & & $\begin{array}{c}\text { On the maximum ten loan } \\
\text { concentration }\end{array}$ & 0.1118 \\
\hline & & & \multirow{3}{*}{ Profitability } & \multirow{3}{*}{0.0819} & Roe & 0.0410 \\
\hline & & & & & Operating income growth rate & 0.0410 \\
\hline & & & & & Deposit growth rate & 0.0218 \\
\hline & & & \multirow[t]{2}{*}{ Development ability } & \multirow[t]{2}{*}{0.0654} & Loan growth rate & 0.0218 \\
\hline & \multirow{8}{*}{$\begin{array}{l}\text { External } \\
\text { factors }\end{array}$} & \multirow{8}{*}{0.2500} & & & Bad loan balance drop rate & 0.0218 \\
\hline & & & \multirow{2}{*}{$\begin{array}{l}\text { Economic } \\
\text { environment }\end{array}$} & \multirow{2}{*}{0.1621} & Enterprise scale benefit & 0.1081 \\
\hline & & & & & Local economic situation & 0.0540 \\
\hline & & & \multirow{2}{*}{ Financial supervision } & \multirow{2}{*}{0.0305} & Supervision strength & 0.0076 \\
\hline & & & & & Supervision level & 0.0229 \\
\hline & & & \multirow{3}{*}{ Moral construction } & \multirow{3}{*}{0.0574} & $\begin{array}{c}\text { Information symmetry construction } \\
\text { level }\end{array}$ & 0.0281 \\
\hline & & & & & Institution moral level & 0.0143 \\
\hline & & & & & Borrower moral level & 0.0150 \\
\hline
\end{tabular}

Based on Risk Evaluation Index System of NRFI, we selected the appropriate samples for empirical analysis. Taking into account the sample enterprises in the enterprise size, set-up time, the main business nature, geographical location and other aspects of comparability, we selected Lucheng Bank and Hakka Bank as empirical samples. We further collected the data on 2015Q2 (the end of the 2nd quarter in 2015, next meant same), 2015Q4, 2016Q2 and 2016Q4 by referring to the annual reports and the interview surveys.

Based on the index system above, we calculated the risk value of the sample institutions. As the indexes could be divided into two attributes, namely, the quantitative and the qualitative, therefore, the calculation in empirical part included two methods. Firstly, calculated the risk value of quantitative indexes. The internal factors were quantitative indicators, we need to standardize the indicators by formula (1).

$\mathrm{B}^{\prime}=1 /[1+(\mathrm{X}-\mathrm{B})]$

B' was standardized value, $\mathrm{X}$ was actual value, $\mathrm{B}$ was the standard value of the index. The standard values of the index system we used were from the Core Indexes of the Risk Supervision of Commercial Banks (Trial) promulgated by the China Banking Regulatory Commission (2005). Further, we calculated the values of all quantitative indicators, combining the total weight of the three indicators. Secondly, we calculated the risk value of quantitative ones. External factors were qualitative, considering the difficulties of measurement, we inferred the values of qualitative indicators by statistical converting method. Based on the weight of internal factors and external factors, we defined formula 2.

Qualitative indicator value $=$ Corresponding quantitative indicator value $* 0.2500 / 0.7500$ 
According to source data of Lucheng Bank and Hakka Bank in 2015 and 2016, we averaged the secondary indexes of the four time points to get Table 2, and the total index of the average value was the total value of the enterprise risk.

Table 2. Average value of Level 2 indicator

\begin{tabular}{ccc}
\hline Level 2 indicator & Lucheng Bank & Hakka Bank \\
\hline Capital adequacy & 0.1444 & 0.1589 \\
Liquidity & 0.1434 & 0.1632 \\
Safety & 0.3535 & 0.3318 \\
Profitability & 0.0832 & 0.0750 \\
Development ability & 0.0757 & 0.0754 \\
Economic environment & 0.1729 & 0.1738 \\
Financial supervision & 0.0325 & 0.0327 \\
Moral construction & 0.0612 & 0.0616 \\
Total & 1.0502 & 1.0542 \\
\hline
\end{tabular}

Combined the above index system with table 1 and table 2, we analyzed the risk values of the two sample firms: (1) From the overall risk value of Lucheng Bank and Hakka Bank's, the average risk value were close and both shown a downward trend. However, from the trend of four time points, the risk value of Lucheng Bank was more negative than Hakka Bank, and the relative value of risk increased. Further, from the point of view of the sub-index, the increase in the total risk value of the Lucheng Bank was caused by the increase of safety factor, the level 2 index with biggest weight. In next stage, we analyzed eight secondary dimensions, including safety dimension and put forward corresponding countermeasures and suggestions. (2) The weight of internal factors was 0.7500 , was 3 times external factor in level 1 indexes. In the case of Lucheng Bank, the internal risk value calculated was higher than the external one. By 2015 Q2, the ratio was 2, and the ratio was expanded to 3 by 2016 Q4, which reflected the impact of internal factors on the overall risk of NRFI. Reducing risk need to focus on internal factors, including management of capital adequacy, liquidity, security, effectiveness, and capacity for development. For Lucheng Bank, the development of whom was less than 8 years, the same for the NRFI as a whole system, the internal control mechanism was not perfect in general, the lack of management experience was also an important reason for higher internal factors risk value. Lucheng Bank was the first listed NRFI in Jiangsu Province, was currently one of the few listed NRFI in China , compared to the general NRFI, Lucheng Bank got better perfection in the company system and internal control, so for a wider level of NRFI, in particular, need to pay attention to risk control of the internal factors. (3) The weight of safety dimension was 0.2795 , ranked first in 8 secondary indicators, which reflected the absolute importance of safety dimension both in internal factors and even the whole evaluation system, which was also the common attribute in the whole financial industry [10]. In the empirical analysis, the safety value of Lucheng Bank has been increasing slowly in the past two years. The safety risk value at the end of 2016 was $1.78 \%$ higher than that in 2015, which reflected that the safety risk increased slowly. In the view of level 3 indicators of the safety, Lucheng Bank's non-performing loan rate was declining in the past two years, which was conducive to the control of safety risk, and a single largest customer loan ratio and the maximum ten loan concentration had increased, which meant the hidden safety risks had increased, so it was need to focus on reducing the concentration of loans to control the risk. In the same time range, the safety risk value of Hakka Bank decreased by $1.31 \%$ due to the risk control of the single largest customer loan proportion index. The opposite trend of the safety value of the two sample firms plus the heavy weight made the safety risk of Lucheng Bank more prominent. (4) In internal factors, the weight of capital adequacy and liquidity was just next to safety. Capital adequacy was an important indicator of the robustness, while liquidity reflected the liquidity of the organization, the faster the flow of assets brought the stronger profitability of financial institutions. NRFI operated mainly for the rural financial market, characteristics of the "Three Rural" made the savings and investment weak and seasonal, which required great safety and liquidity for the financial institutions. Over the past two years, the capital adequacy risk value of Hakka Bank showed a slow downward trend, but was still higher than Lucheng Bank by nearly 10 percentage in average. Further from view of level 3 indicators, 
it was need to focus on solving the problem of low provision coverage. The fluidity risk value of Lucheng Bank had fluctuated slightly in the past two years, but the overall risk value was still increasing. The risk fluctuation in reasonable range of was normal for financial system because of the strong fluidity, especially for the rural financial system. However, the liquidity risk value of Hakka Bank was significantly too large, the average value was larger than Lucheng Bank by $13.80 \%$ in observation range, there was need to control the too fast increase of liquidity risk by collaborative management of deposit and loan ratio and the proportion of funds. (5) In external factors, the weight of economic environment was 0.1621 , was far more than the weight of financial supervision and moral construction, even more than the development of enterprises and the profitability in the internal factors, which reflected the important influence of the local economic development and the scale effect of the local financial institutions on the risk of NRFI. The local economic development played an important role in the sound operation and development of the financial institutions. The headquarters of Lucheng Bank locates in Suzhou, Jiangsu Province, which is one of the most important cities in economic development, As for Hakka Bank, which locates in Meizhou, Guangdong Province. The advantages of industrial agglomeration effect in Suzhou helped reduce the operating risk of Lucheng Bank in a certain, and thus the total value of external risk on the Lucheng Bank was slightly lower than Hakka Bank. The main factors that affected the external risk of NRFI included the economic environment, financial supervision and moral construction, the responsible subjects of the first two factors were governmental policy regulation and intra-industrial coordination. The moral construction factor reflected the risks that may arise from the construction of regional moral construction. However, the construction problem of the moral level of financial institutions and borrowers need collaborative solution with efforts from social factor, cultural factor, political factor, economic factor, and so on, which would be a long process.

\section{Acknowledgments}

The research is supported by the postdoctoral research funding scheme of Jiangsu Province (Grant No. 1601065C).

\section{References}

[1]. Zhongming Tan, Jun Liang. Operating risk of rural micro-credit company and its prevention Based on the investigation and analysis of Jiangsu Province. Rural Economy. (2011), No.10, p.51-53.

[2]. Xiaoguang Gao. Research on the Sustainable Development of New Rural Financial Institutions. Contemporary Economic Research. Vol. 233(2015), No.2, p.87-91.

[3]. Guangwei Tian. Risk Generation and Prevention of Rural Financial Institutions in China. Rural Economy. (2015), No.10, p.64-66.

[4]. J Y Wang, X F Wang. Discussion on setting up risk index system of new rural financial institution. Guangdong Agricultural Sciences, (2010), No.4, p.306-309.

[5]. Wenpei Tan. Risk Evaluation and Construction of Early-warning Index System of New Rural Financial Institutions. Social Sciences in Hunan. (2014), No.5, p.131-134.

[6]. Caihong Lan: Research on Risk Management of New Rural Financial Institutions in China. (Doctor, Jilin University of Finance and Economics, China, 2016).

[7]. Tirole. The Theory of Corporate Finance. Princeton university press, 2006, p.131-133.

[8]. Zheng Hong. Is It Feasible to Reform New Rural Financial Institutions? - An Analysis Based on the Perspective of Monitoring efficiency. Economic Research Journal. (2011), No.2, p.44-58.

[9]. Chuanliang Zhang, Dongling Weng. Study on the Moral Hazard of China's Village Bank Deposit Insurance System. Asia-pacific Economic Review. (2013), No.6, p.34-39.

[10]. Yingmei Xu, Lu Xu. A Study on the Cross-market Risk Among China's Financial Sectors: Based on LARCH-Copula-CoVaR Model. Statistics \& Information Forum. (2015), No.4, p.2832. 